\title{
Evaluation of Cardiac Risk Score and Quality of Life Survey in Taiwan Chronic Hemodialysis Patients
}

\author{
Ing-Fang Yang ${ }^{1,2,}$, Ten-Fang Yang ${ }^{2,3}$, Ming-Hsien Chou ${ }^{4}$, Ching-Ching Lin $^{5}$ and Ming-Hsun Yang ${ }^{6}$ \\ ${ }^{1}$ Department of Internal Medicine and Nephrology, Jen-Chi General Hospital, Taipei, Taiwan \\ ${ }^{2}$ Faculty of Medicine and Cardiology Department, Taipei Medical University, Taipei, Taiwan \\ ${ }^{3}$ College of Biologic Science \&Technology, ChiaoTung University, Taiwan \\ ${ }^{4} \mathrm{Ho}$-TaiClinic, Taipei, Taiwan \\ ${ }^{5}$ Chang-Gung University, Guishan, Taoyuan, Taiwan \\ ${ }^{6}$ Tsinghua University, Beijing, China
}

\begin{abstract}
Publication History:

The purpose of this study is to analyze the independent clinical, laboratory, dialysis factors between Received: July 16, 2018 a disease-specific score for cardiac risk stratification and the Quality of life (QOL) application in Accepted: September 17, 2018 hemodialysis (HD) patients. A total of 43 end-stage renal disease patients (female 17 and male 26) Published: September 19, 2018 on regular HD were included. They were clinically stable with a mean Kt/V (Daugirdas) $1.76 \pm 0.41$ and mean dialysis 7.4 \pm 0.94 years. Patients answered the Kidney Disease Quality of Life questionnaire Keywords: short form (KDQOL-SF) which includes the physical and mental health component (PHC, MHC). Application of a previously validated cardiac risk score (CRS) using cardiac history (A), dialysis Cardiac risk score, Quality of life, duration (B), body mass index (C) and serum phosphate (D) multiplied by various hazards ratio (HR) Hemodialysis, Body mass index, was also investigated retrospectively. CRS $(A+B+C+D)<50$ allocated low risk, and CRS $\geq 50$ stands for Physical health component high risk of future cardiac events. The impact of various factors on CRS and KDQOL-SF was estimated by multivariate analysis using SPSS 10.0 depending on variables characteristics.
\end{abstract}

Most of the KDQOL-SF scores specific for dialysis significantly correlated with Hct, albumin, electrolytes, age, dose of HD and social support $(\mathrm{P}<0.01)$. CRS $\geq 50$ was found in 19 patients and 6 had cardiac events after electrocardiography and cardiac stress imaging proven in the following observed 9 months period. CRS $<50$ were in the remaining 24 patients with 1 cardiac event occurred. Physical health component (PHC) and mental health component (MHC) in QOL were significant in CRS $\geq 50$ group $(\mathrm{P}<0 / 01)$, while only MHC in QOL was found relating in $\mathrm{CRS}<50$ group $(\mathrm{P}<0 / 01)$. Dialysis year was irrelevant to the QOL statistically, but proportionate with CRS. Greater PHC and MHC score in QOL with less CRS value is found among younger, shorter dialysis duration, sufficiently correction of serum electrolytes including phosphate toward normal, adequate social and emotional interaction HD patients.

\section{Introduction Materials and Methods}

Despite the flashing advances in medical science investigation and clinical therapy, population of end-stage renal disease (ESRD) with subsequent renal replacement therapy patients is still growing annually [1]. Approximately half of the annual mortality (6-9\%) of CRF patients can attribute to the cardiovascular diseases [2]. Cardiac disease is also common in pre-dialysis chronic kidney disease patients and occurs with increasing frequency, severity and mortalityassociated risk as renal function deteriorated $[3,4]$. Recently, quality of life (QOL) among chronic hemodialysis (HD) patients becomes an important parameter of the treatment adequacy and deserves various clinical investigations, especially cost-effectiveness relation under government insurance coverage [5,6]. HD patients can have impaired daily functioning because of their primary kidney disease and comorbid conditions [7]. Among these efforts, the role of assessments of health-related QOL (HRQOL) by the application of generic and specific measures that are used to examine which dimensions or areas in patients' life are impaired and necessitate an appropriate intervention is particularly important $[8,9]$. Self-efficacy of patient-oriented point of view can be of great value in the evaluation of treatment outcome and dialysis course $[10,11]$. The aim of this study was to analyze the association between independent clinical, laboratory, dialysis factors and self-efficacy of the QOL with HD treatment outcome which will be compared with a validated disease-specific score for cardiac risk stratification [12-14] and the QOL application in HD patients [15].
There were 43 patients ( 17 men and 26 women, aged $55.2 \pm 12.31$ years old) undergoing long-term maintenance thrice weekly HD therapy recruited in this study. Patients answered the Kidney Disease Quality of Life questionnaire (KDQOL-SF ${ }^{\mathrm{TM}}$ ) which includes the SF-36 (8 dimensions/36 items): physical functioning (10 items), role limitations caused by physical problems (4 items), role limitations caused by emotional problems ( 3 items), pain ( 2 items), general health perceptions ( 5 items), social functioning ( 2 items), emotional well-being (5 items), energy/fatigue (4 items), and 1 item about health status compared to one year ago; kidney-disease-targeted items (11dimensions/43 items); symptom/problem list (12 items), effects of kidney disease (8 items), burden of kidney disease (4 items), cognitive function (3 items), quality of social interaction (3 items), sexual function (2 items), sleep (4 items), social support (2 items), work status ( 2 items), overall health rating ( 1 item scored separately),

*Corresponding Author: Dr. Ing-Fang Yang, Department of Internal Medicine and Nephrology, Jen-Chi General Hospital, Taipei, Taiwan; Email: renalman@gmail.com

Citation: Yang IF, Yang TF, Chou MH, Lin CC, Yang MH, et al. (2018) Evaluation of Cardiac Risk Score and Quality of Life Survey in Taiwan Chronic Hemodialysis Patients. Int J Community Fam Med 3: 144. https://doi.org/10.15344/24563498/2018/144

Copyright: (c) 2018 Yang et al. This is an open-access article distributed under the terms of the Creative Commons Attribution License, which permits unrestricted use, distribution, and reproduction in any medium, provided the original author and source are credited. 
Citation: Yang IF, Yang TF, Chou MH, Lin CC, Yang MH, et al. (2018) Evaluation of Cardiac Risk Score and Quality of Life Survey in Taiwan Chronic Hemodialysis Patients. Int J Community Fam Med 3: 144. https://doi.org/10.15344/2456-3498/2018/144

Page 2 of 5

patient satisfaction (1 item), and dialysis staff encouragement (2 items). Self-efficacy scoring system developed locally which is divided into two dimensions; self-awareness (11 items), and self-care (5 items) also added in the questionnaire. Clinical data including dialysis treatment type and co-morbidity (cardiovascular diseases, chronic obstructive lung disease, peripheral vascular disease, diabetes mellitus, cerebrovascular disease, liver disease, hypertension, visual deficit, ambulation deficit, and cancer) were recorded and analyzed. Laboratory parameters including electrolytes, HD efficiency data (e.g.: Kt/V, nPCR, URR), albumin and creatinine were also analyzed. Application of a previously validated cardiac risk score (CRS) using cardiac history (A), dialysis duration (B), body mass index (C) and serum phosphate (D) multiplied by various hazards ratio (HR) was also investigated retrospectively. CRS $(\mathrm{A}+\mathrm{B}+\mathrm{C}+\mathrm{D})<50$ allocated low risk, and CRS $\geq 50$ stands for high risk of future cardiac events. The impact of various factors on CRS and various factors on KDQOL-SF ${ }^{\mathrm{TM}}$ were estimated by multivariate analysis using SPSS $^{\star} 10.0$ depending on variables' characteristics. Cox's regression analysis for relative laboratory and clinical outcome also performed. The tests were twotailed and $\mathrm{P}<0.05$ was considered to indicate statistical significance.

\section{Results}

HRQOL dimension scores of KDQOL-SF ${ }^{\text {su }}$ questionnaire (Table 1) obtained from the HD patients is significantly $(\mathrm{P}<0.001)$ lower as comparing with the scores obtained from the normal control in Taiwanese population (Figure 1). Self efficacy was significantly related to the overall health $(\mathrm{P}<0.01)$ and physical functioning items $(\mathrm{P}<0.01)$. One of the HD efficiency data (nPCR) was also significantly related to cognitive function and quality of social interaction dimensions in KDQOL. Except for the mean dialysis age 7.4 \pm 0.94 years is not statistically significant to the self efficacy and health care, or the KDQOL scores. Patients with older age had lower KDQOL coefficients' scores (Table 2). In comparison with the KDQOL dimensions, correlation coefficients were statistically significant for the following laboratory data (Table 3$)$ : potassium $(\mathrm{P}<0.01)$, calcium $(\mathrm{P}<0.05)$, phosphate $(\mathrm{P}<0.01)$, creatinine $(\mathrm{P}<0,01)$, and albumin $(\mathrm{P}<0.01)$. Hct was inversely significant in patient satisfaction and dialysis staff encouragement, but significant in dialysis year and patients' age.

CRS $\geq 50$ was found in 19 patients and 6 had cardiac events after electrocardiography and cardiac stress imaging proven in the following observed 9 months period. CRS $<50$ were in the remaining 24 patients with 1 cardiac event occurred. PHC and MHC in QOL were significant in $C R S \geq 50$ group $(P<0 / 01)$, while only MHC in QOL was found relating in CRS $<50$ group $(\mathrm{P}<0 / 01)$. Dialysis year was irrelevant to the QOL statistically, but proportionate with CRS.

\section{Discussion}

The methods used to evaluate the quality of life questionnaires in nephrology are not adequate and impractical as compared with the normal population ones [16]. It is also important to determine whether intra-observer and inter-observer of the self-applied procedure or application of the questionnaire is reliable to reflect clinical changes over times in the dialysis treatment course $[17,18]$. Additional problems are the wrong choice of questionnaire or problems with its utilization [19]. The KDQOL-SF ${ }^{\mathrm{TM}}$ has many advantages compared to other instruments e.g. it has been tested in several populations with kidney disease, it has both general and specific modules to access chronic kidney disease, it has questions about the sexual area and professional rehabilitation, and it can be self-applied or applied by the interviewer [20]. Self-efficacy and health care added in KDQOL-SF ${ }^{\mathrm{mm}}$ as a whole to investigate the exact quality of patients on regular hemodialysis proved to be a effective tool not

\begin{tabular}{|c|c|c|}
\hline Dimension & Mean \pm SD & Minimum-Maximum \\
\hline General health & $40.83 \pm 19.03$ & $5-95$ \\
\hline Physical functioning & $67.00 \pm 29.61$ & $0-100$ \\
\hline Role limitations--physical & $43.33 \pm 44.01$ & $0-100$ \\
\hline Role limitations--emotional & $63.33 \pm 45.78$ & $0-100$ \\
\hline Pain & $67.67 \pm 30.06$ & $10-100$ \\
\hline Social function & $70.00 \pm 29.10$ & $0-100$ \\
\hline Emotional well-being & $61.33 \pm 22.19$ & $16-96$ \\
\hline Energy/fatigue & $48.17 \pm 22.30$ & $10-85$ \\
\hline Burden of kidney disease & $36.46 \pm 20.44$ & $6.25-81.25$ \\
\hline Cognitive function & $72.67 \pm 22.17$ & $20-100$ \\
\hline Quality of social interaction & $72.44 \pm 23.14$ & $13.33-100$ \\
\hline Symptom/problem list & $65.76 \pm 16.74$ & $29.17-97.92$ \\
\hline Effects of kidney disease & $51.56 \pm 24.83$ & $3.13-96.88$ \\
\hline Sexual function & $71.25 \pm 22.09$ & $25-100$ \\
\hline Sleep & $63.92 \pm 16.99$ & $30-95$ \\
\hline Social support & $56.11 \pm 26.80$ & $0-100$ \\
\hline Work status & $53.33 \pm 39.25$ & $0-100$ \\
\hline Patient satisfaction & $60.00 \pm 22.99$ & $33.33-100$ \\
\hline Dialysis staff encouragement & $67.50 \pm 28.16$ & $12.50-100$ \\
\hline
\end{tabular}


Citation: Yang IF, Yang TF, Chou MH, Lin CC, Yang MH, et al. (2018) Evaluation of Cardiac Risk Score and Quality of Life Survey in Taiwan Chronic Hemodialysis Patients. Int J Community Fam Med 3: 144. https://doi.org/10.15344/2456-3498/2018/144

Page 3 of 5

only in predicting the outcome of dialysis patients, but the costeffectiveness among medical intervention needed [21]. We conclude that QOL analyses are particularly helpful for investigating the social, emotional and physical effects of treatment and disease processes on ESRD patients' daily lives [22]. From this study, it is obvious that the older the patients' age, the less scores he will acquire. However, patients undergoing dialysis did not have lower scores with longer dialysis years. This implied that an intensive bedside assistance and continuous workup with quality survey monitoring will further profit the patients on dialysis, no matter how long they were on dialysis. As expected, the best correlation between KDQOL-SF $F^{m}$ and laboratory data was electrolytes, nutritional status and HD efficiency. Overall, greater dose of HD on high-flux membranes, sufficiently correction of serum electrolytes toward normal value and adequate social and emotional interaction with HD patients can also reflect better outcome [23,24].Greater PHC and MHC score in QOL with less CRS value is found among younger, shorter dialysis duration, sufficiently correction of serum electrolytes including phosphate toward normal,

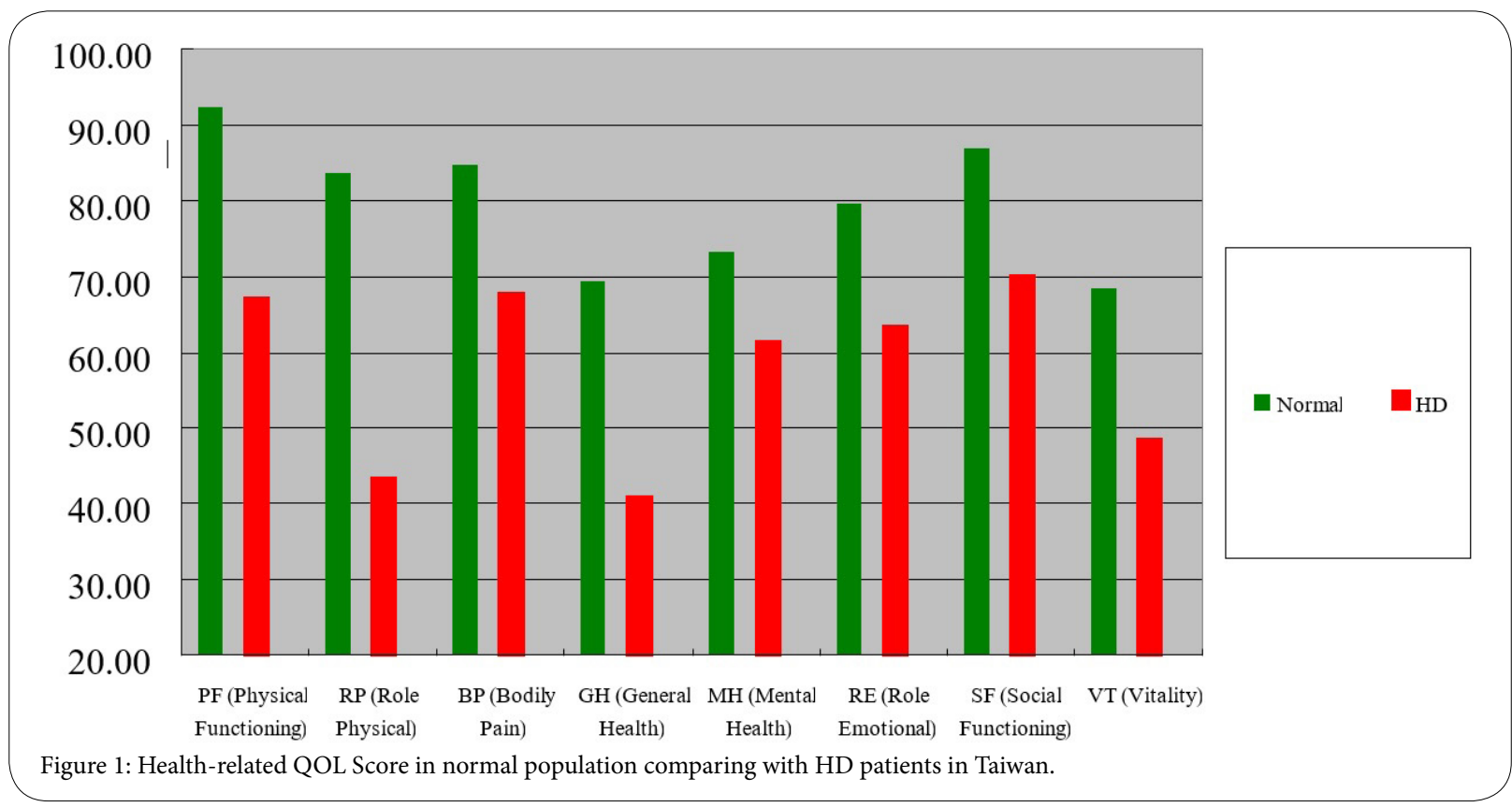

\begin{tabular}{|c|c|c|c|c|}
\hline Dimension & Self Efficacy & nPCR & Kt/V(Daugirdas) & Age \\
\hline General health & $.513^{* *}$ & .221 & -.132 & -.358 \\
\hline Physical functioning & $.784^{* *}$ & .272 & .094 & $-.647^{\star *}$ \\
\hline Role limitations--physical & $.443^{*}$ & -.001 & -.274 & $-.548^{\star *}$ \\
\hline Role limitations--emotional & $.384^{*}$ & .086 & -.252 & $-.441^{\star}$ \\
\hline Pain & $.399^{*}$ & .252 & .044 & -.253 \\
\hline Social function & $.568^{\star *}$ & .393 & -.016 & -.356 \\
\hline Emotional well-being & $.608^{* *}$ & .320 & -.080 & $-.557^{\star *}$ \\
\hline Energy/fatigue & $.711^{* *}$ & .400 & .023 & $-.563^{* *}$ \\
\hline Burden of kidney disease & $.529^{* *}$ & .314 & .016 & $-.588^{\star *}$ \\
\hline Cognitive function & $.654^{* *}$ & $.572^{*}$ & .109 & -.326 \\
\hline Quality of social interaction & $.473^{* *}$ & $.631^{* *}$ & .070 & -.336 \\
\hline Symptom/problem list & .301 & .291 & .073 & -.105 \\
\hline Effects of kidney disease & $.730^{* *}$ & .376 & .036 & $-.520^{\star *}$ \\
\hline Sexual function & .417 & .557 & .203 & $-.696^{*}$ \\
\hline Sleep & .244 & .285 & -.218 & -.345 \\
\hline Social support & $.603^{* *}$ & $.580^{*}$ & .135 & -.225 \\
\hline Work status & .352 & .306 & -.093 & $-.519^{\star \star}$ \\
\hline Patient satisfaction & -.061 & .136 & .083 & .331 \\
\hline Dialysis staff encouragement & .047 & .232 & .082 & .142 \\
\hline
\end{tabular}


Citation: Yang IF, Yang TF, Chou MH, Lin CC, Yang MH, et al. (2018) Evaluation of Cardiac Risk Score and Quality of Life Survey in Taiwan Chronic Hemodialysis Patients. Int J Community Fam Med 3: 144. https://doi.org/10.15344/2456-3498/2018/144

Page 4 of 5

\begin{tabular}{|c|c|c|c|c|c|c|}
\hline Dimension & $\mathrm{K}$ & $\mathrm{Ca}$ & $\mathrm{P}$ & Creatinine & Albumin & Hct \\
\hline General health & .201 & .167 & .136 & .316 & .232 & -.056 \\
\hline Physical functioning & $.478^{\star *}$ & $.467^{\star *}$ & .285 & $.694^{* *}$ & $.523^{\star *}$ & .287 \\
\hline Role limitations--physical & .093 & .026 & .013 & .199 & .172 & .077 \\
\hline Role limitations--emotional & .234 & .304 & .090 & .354 & $.449^{*}$ & .132 \\
\hline Pain & .247 & .183 & .147 & .347 & .284 & .044 \\
\hline Social function & .259 & .207 & .170 & $.416^{*}$ & .241 & -.101 \\
\hline Emotional well-being & $.415^{\star}$ & .285 & .211 & $.415^{*}$ & $.552^{\star *}$ & .043 \\
\hline Energy/fatigue & .341 & .318 & .242 & $.464^{* *}$ & $.437^{\star}$ & -.047 \\
\hline Burden of kidney disease & .306 & .220 & .285 & .215 & $.378^{*}$ & -.083 \\
\hline Cognitive function & $.468^{\star *}$ & .314 & .294 & $.495^{\star *}$ & $.389^{*}$ & -.092 \\
\hline Quality of social interaction & $.454^{\star}$ & .184 & $.386^{*}$ & $.384^{*}$ & .308 & -.169 \\
\hline Symptom/problem list & .170 & .284 & .194 & .347 & .201 & -.016 \\
\hline Effects of kidney disease & $.363^{*}$ & .197 & .277 & $.386^{*}$ & $.551^{\star *}$ & .064 \\
\hline Sexual function & .090 & .159 & .417 & .197 & .507 & -.030 \\
\hline Sleep & .143 & .180 & .240 & .071 & $.524^{\star *}$ & -.246 \\
\hline Social support & $.473^{\star *}$ & .245 & $.388^{\star}$ & .251 & $.521^{\star *}$ & -.202 \\
\hline Work status & .317 & .085 & .185 & .312 & .244 & .281 \\
\hline Patient satisfaction & -.219 & -.188 & .114 & -.066 & $-.519^{* *}$ & $-.374^{\star}$ \\
\hline Dialysis staff encouragement & -.329 & -.334 & .087 & -.103 & $-.383^{*}$ & $-.458^{\star}$ \\
\hline Self Efficacy & $.630^{* *}$ & $.371^{\star}$ & $.487^{\star *}$ & $.546^{\star *}$ & $.494^{\star *}$ & .178 \\
\hline Health Care & $.623^{\star *}$ & $.480^{* *}$ & $.517^{\star *}$ & $.427^{\star}$ & $.608^{\star *}$ & $.419^{*}$ \\
\hline Age & -.325 & -.261 & -.297 & $-.382^{\star}$ & $-.481^{\star *}$ & -.260 \\
\hline Dialysis year & $.390^{*}$ & .145 & .179 & $.438^{*}$ & .202 & $.393^{*}$ \\
\hline
\end{tabular}

Table 3: Laboratory data correlation with KDQOL.

${ }^{*} \mathrm{p}<0.05,{ }^{* *} \mathrm{p}<0.01$

adequate social and emotional interaction HD patients. Application with a combination of CRS and KDQOL-SF ${ }^{\mathrm{TM}}$ can significantly enhance their role as a justified non-invasive tool for the need to screen HD patients at risk of cardiac events [25,26].

\section{Competing Interests}

The authors declare that they have no competing interests.

\section{References}

1. Himmelfarb J, Ikizler TA (2010) Hemodialysis. N Engl J Med 363: 1833-1845

2. Parfrey PS, Folley RN (1999) The clinical epidemiology of cardiac disease in chronic renal failure. J Am Soc Nephrol 10: 1606-1615.

3. Young EW, Goodkin DA, Mapes DL, Port FK, Keen ML, et al. (2000) The Dialysis Outcomes and Practice Patterns Study (DOPPS): An internationa hemodialysis study. Kidney Int 57: S74-S81

4. Cheung AK, Sarnak MJ, Yan G, Berkoben M, Heyka R, et al. (2004) Cardiac diseases in maintenance hemodialysis patients: results of the HEMO study. Kidney Int 65: 2380-2389.

5. Perneger TV, Leski M, Chopard-Stoermann C, Martin PY (2003) Assessment of health status in chronic hemodialysis patients. J Nephrol 16: 252-259.

6. Samak MJ (2000) Cardiovascular mortality in the general population and dialysis patients. Am J Kidney Dis 35: 117-135.

7. Tseng HM, Lu JR, Tsai YJ (2003) Assessment of health-related quality of life in Taiwan version (II). Taiwan J Public Health 22: 512-518.
8. Sesso R, Yoshihiro MM (1997) Time of diagnosis of chronic renal failure and assessment of quality of life in hemodialysis patients. Nephrol Dial Transplant 12: 2111-2116

9. Sathvik BS, Parthasarathi G, Narahari MG, Gurudev KC (2008) An assessment of the quality of life in hemodialysis patients using the WHOQOL-BREF questionnaire Indian. J Nephrol Oct 18): 141-149.

10. Zyoud SH, Daraghmeh DN, Mezyed DO, Khdeir RL, Sawafta MN et al. (2016) Factors affecting quality of life in patients on haemodialysis: a crosssectional study from Palestine BMC Nephrol 17: 44.

11. Carmichael P, Popoola J, John I, Stevens PE, Carmichael AR, et al. (2000) Assessment of quality of life in a single center dialysis population using the KDQOL-SF questionnaire. Qual Life Res Mar 9: 195-205.

12. Chang JF, Chan CL, Chou MH, Yang TF, Yang IF, et al. (2005) Assessment of the Self-efficacy and Treatment Outcome Relationship in Chronic Hemodialysis Patients in Taiwan-Using KDQOL-SFTM Health Measurement. Annual Proceeding of Taiwan Society of Internal Medicine 2.

13. Armstrong KA, Rakhit DJ, Case C, Johnson DW, Isbel NM, et al. (2005) Derivation and Validation of a disease-specific risk score for cardiac risk stratification in chronic kidney disease. Nephrol Dial Transplant 20: 20972104.

14. Nakamura S, Uzu T, Inenaga T, Kimura G (2000) Prediction of coronary artery disease and cardiac events using electrocardiographic changes during hemodialysis. Am J Kidney Dis 36: 592-599.

15. Yoshino $M$, Kuhlmann MK, Kotanko P, Greenwood RN, Pisoni RL, et al (2006) International differences in dialysis mortality reflect background general population atherosclerotic cardiovascular mortality. J Am Soc Nephrol 17: 3510-3519.

16. Mapes DL, Lopes AA, Satayathum S, McCullough KP, Goodkin DA et al. Health-related quality of life as a predictor of mortality and hospitalization: The Dialysis Outcomes and Practice Patterns Study (DOPPS). Kidney Int 64 339-349. 
Citation: Yang IF, Yang TF, Chou MH, Lin CC, Yang MH, et al. (2018) Evaluation of Cardiac Risk Score and Quality of Life Survey in Taiwan Chronic Hemodialysis Patients. Int J Community Fam Med 3: 144. https://doi.org/10.15344/2456-3498/2018/144

Page 5 of 5

17. Ricardo AC, Hacker E, Lora CM, Ackerson L, DeSalvo KB, et al. (2011) 264 validation of the kidney disease quality of life 36 (KDQOL-36) U.S. Spanish and English versions in Hispanic with chronic kidney disease. American Journal of Kidney Disease 57: B82.

18. Yang SC, Kuo PW, Wang JD, Lin MI, Su S, et al. Quality of life and its determinants of hemodialysis patients in Taiwan measured with WHOQOLBREF(TW). American Journal of Kidney Diseases 46: 635-641.

19. Soni RK, Weisbord SD, Unruh ML (2010) Health-related quality of life outcomes in chronic kidney disease. Curr Opin Nephrol Hypertens 19: 153159

20. Tajima R, Kondo M, Kai H, Saito C, Okada M, et al. (2010) Measurement of health-related quality of life in patients with chronic kidney disease in Japan with EuroQol (EQ-5D). Clinical and Experimental Nephrology 14: 340-348.

21. Tsai YC, Hung CC, Hwang SJ, Wang SL, Hsiao SM, et al. (2010) Quality of life predicts risks of end-stage renal disease and mortality in patients with chronic kidney disease. Nephrol Dial Transplant 25: 1621-1626.

22. Mittal SK, Ahern L, Flaster E, Maesaka JK, Fishbane S, et al. (2001) Selfassessed physical and mental function of haemodialysis patients. Nephro Dial Transplant 16: 1387-1394.

23. Koefoed $M$, Kromann $C B$, Hvidtfeldt $D$, Juliussen $S R$, Andersen JR, et al. (2016) Historical Study (1986-2014): Improvements in Nutritional Status of Dialysis Patients. J Renal Nutrition 26: 320-324.

24. Oshvandi K, Kavyannejad R, Borzuo SR, Gholyar M (2014) High-Flux and Low-Flux Membranes: Efficacy in Hemodialysis. Nurs Midwifery Stud 3 e21764.

25. Foley RN, Gilbertson DT, Murray T, Collins AJ (2011) Long interdialytic interval and mortality among patients receiving hemodialysis. N Engl J Med 365: 1099-1107.

26. Hage FG, Venkataraman R, Zoghbi GJ, Perry GJ, DeMattos AM, et al. (2009) The scope of coronary heart disease in patients with chronic kidney disease. J Am Coll Cardiol 53: 2129-2140. 